\title{
Modeling of strategic accounting of counterparties in the management of tour operators ' activities
}

\author{
Petr Shumilin ${ }^{1, *}$,Ekaterina Davydova ${ }^{1}$, Olga Dudkina $^{1}$, and Elena Egorova ${ }^{1}$ \\ ${ }^{1}$ Don State Technical University, 1, Gagarin Sq., 344003, Rostov-on-Don, Russia
}

\begin{abstract}
The efficiency of the tourism business and its profitability largely depend on the management methods. An important role is played by an accounting and analytical system that generates relevant management indicators that allow you to flexibly respond to changing external conditions. A model of strategic accounting of tour operator counterparties is proposed. The article substantiates the exceptional importance of comprehensive accounting of counterparties for the formation of a competitive tourist product.
\end{abstract}

\section{Introduction}

Tourism is an important sector of the world economy, and its contribution to world exports and GDP is about $10 \%$. There are countries in which tourism is the main source of GDP creation, for example, the Maldives, Antigua and Barbuda, Seychelles, Macau, the Bahamas are the Top 5 countries in which the economy relies on tourism. The share of the Russian tourism industry is estimated at $1-3 \%$ of GDP, it is very small, and has prospects for significant further growth. The tourism economy is a multidimensional phenomenon, which can be seen in Figure 1.

In this regard, it seems relevant to consider the issues of tourism economics at the micro level in terms of tourism management. In our opinion, the tourism business is a good niche for investment in a country like Russia, and the capital of tourism companies has a great chance of growth. At the same time, we predict the consolidation of travel companies, the emergence of market players who are able to bring their shares to the stock exchange to attract capital. Thus, the issue of management efficiency comes to the fore, which allows us to maintain the pace of sustainable development and steady growth of the company's capital.

Management efficiency largely depends on the accounting information system to collect current information about the object and provide it in the form of relevant reports, allowing you to make timely management decisions aimed at further development and minimizing hedging risks, higher profits and, as a result, dividend payments to shareholders, the growth of the market multipliers of the company.

\footnotetext{
*Corresponding author: petr_shumilin_ml@mail.ru
} 


\begin{tabular}{|c|c|}
\hline $10 \times 1$ & Segment \\
\hline \multicolumn{2}{|l|}{ 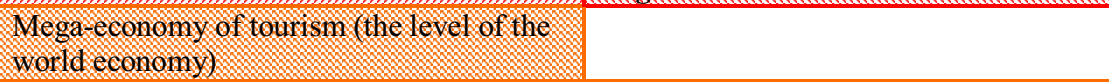 } \\
\hline & Tourism industry in general \\
\hline \multicolumn{2}{|l|}{$\begin{array}{l}\text { Macroeconomics tourism (level of the } \\
\text { national economy) }\end{array}$} \\
\hline & The country's tourism industry \\
\hline \multicolumn{2}{|l|}{ 6 - } \\
\hline & Tourisin industry destinations: \\
\hline \multirow[t]{2}{*}{ 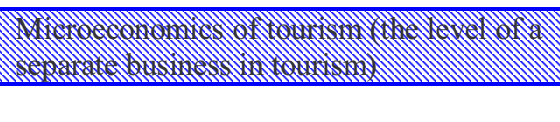 } & \\
\hline & 10 \\
\hline
\end{tabular}

Fig. 1. The relationship between the levels and segments of the tourism industry.

This study is based on statistical materials of the tourism business of the Russian Federation. The main disadvantage of the management of domestic tour operators is the lack of a well-established accounting system based on modern types of accounting and forming adequate management indicators. In our opinion, the management of the tour operator's activities should be based on an accounting and analytical system that reflects the real economic effect of the activity.

\section{Materials and Methods}

When starting to build an accounting and analytical system for managing tourism activities, it is necessary to identify the main object of management. From our point of view, such an object is a tourist product that includes a tour, additional services and goods. Thus, the tour is the main object of accounting for income and expenses, according to which it is advisable to determine performance indicators in order to make a management decision on the further promotion or closure of the tour.

In the formation of sebestoimosti round huge contribution of commercial relations with partners-postaciami services, forming the product, such as transportation, accommodation, food and restaurants, entertainment, sports services, travel agents, engaged in promotion of tourism services.

We use the method of accounting and economic modeling in terms of building a model of strategic accounting of tour operator contractors, including carriers, accommodation facilities (hotels), catering companies, excursion services, etc.

In the course of the study, we analyzed thousands of contracts of dozens of travel agencies that form the market background of the local tourist business. The result is disappointing: there are not enough sources of information about the reliability of counterparties, there is no method of comprehensive assessment of counterparties that form the client capital and the complex of business relations of tour operators, there is no use of strategic accounting methods.

In order for the tour operator to function effectively, it is necessary to adhere to a certain strategic orientation towards service providers and travel agents in order to achieve and realize competitive advantages.

Tour operators try to focus on establishing long-term and mutually beneficial relationships with counterparties and develop appropriate strategies (reverse vertical integration strategy (back strategy) along the value chain of the tourist product).

If you start analyzing the costs from the moment of purchase, you can miss all the opportunities to use the links with the tour operator's suppliers. The word "use" does not 
imply that the relationship with suppliers is a game of tug-of-war, that is, if one lost, the other won. Quite the contrary, communication should be regulated in such a way that both the tourist enterprise in question (tour operator) and the counterparty of this enterprise will benefit. Such opportunities can be incredibly important for any tour operator.

When considering the issues of cost analysis and the use of value chains for management, focus on the use of relationships with suppliers, the need to assess the scale of their impact on the travel company.

Suppliers not only produce and supply incoming resources, such as hotel accommodation, transport, restaurant, entertainment, excursions, which the tour operator uses to create a tourist product, but also significantly influence the company's position in terms of cost and differentiation of tourist destinations as the main factors for gaining an advantage in competition.

The analysis of the value chains of the tourist product helps to assess the capacity of the supplier by calculating its contribution to the profit, that is, what percentage of the total profit can be attributed to the supplier. This information can help the firm determine how to use supplier relationships and capitalize on them as an intangible asset.

When studying the service providers that are included in the tourist product, first of all, pay attention to the following characteristics of their activities::

- cost of the service;

- quality assurance;

- time schedule for the delivery of services;

- punctuality and mandatory compliance with the terms of service.

The strategy of concluding contracts with service providers is determined by the following main components:

- service generation channels;

- composition of suppliers;

- sources;

- pricing policy;

- terms of delivery and payment.

At the same time, it is necessary to take into account:

- potential tourist resources;

- location of tourist resources;

- market power of counterparties;

- the threat of the loss of familiar channels of acquisition and tourism resources;

- the possibility of forming a multi-channel system for providing tourist resources.

The analysis of suppliers is aimed at identifying those aspects in the activities of entities that provide the tour operator with transport, tourist accommodation, food, sightseeing and entertainment services, information resources, insurance, etc., on which the efficiency of the company, the cost price and quality of the tourist product produced depend.

Strategic accounting and supplier analysis aims to develop competitive advantage through relationships with service providers, with the result that relationships with suppliers are considered one of the main sources of improving profits and profitability.

The results of the functioning of service providers, the change in the strategy of concluding contracts lead to a change in the allocation of resources and their sources, and, consequently, a change in the financial condition as the state of the assets, liabilities and capital of the travel company. Financial condition of the enterprise is determined by the dynamics of changes of ownership, expressed in market and fair value, resulting in a basic measure of reliability and quality of financial status is the value of the enterprise in the market value of net assets and the fair value of the net liabilities.

The main purpose of strategic accounting is to accumulate information that allows you to manage the organization as a single whole system, as well as its individual components, 
strategic directions of development and growth.

In this regard, it becomes necessary to study the categories of endeavor, territorial fractal, fractal temporary, napravleniyami activity development in conditions of constant changes in the environment, risk and uncertainty with a focus on a holistic approach, i.e. focusing on the segments as components of an enterprise and the implementation of the strengths of the strategic decisions for each individual segment.

Strategic segmental accounting and forecasting in the context of constant changes should focus on the development of the strategy for individual segments and strategic directions, the creation and implementation of new strategies, making flexible decisions in the face of rapid changes in external economic conditions.

Today, most decisions are associated with a certain degree of risk. The task of strategic accounting is to predict the consequences of making a decision, choosing an alternative development option, implementing the strategy in a segmental context, and to assess their impact on the cost of capital of the enterprise, which is associated with the main positions of economic growth.

Segmental accounting allows you to organize the determination of results by main types of activities, internal and external segments, consumer segments, areas of strategic activity of enterprises, i.e. to move away from the boiler method of accounting.

In accordance with PBU 12/2000 "Segment Information", all segments are divided into operational (part of the company's activities for the production of a certain product), geographical (production and sale of goods in a certain geographical region of the organization's activities) and reporting (operational and geographical segments, information on which is subject to mandatory disclosure in the financial statements).

At the same time, the choice of segments is determined based on the prevailing sources, the amount of revenue received (more than $10 \%$ of total revenue), the segment profits received (more than $10 \%$ of total profit), and the nature of the existing risks. The same requirements are met by the International Financial Reporting Standard in relation to business segments.

As a result, separate accounting is organized by segments of assets, liabilities, income, expenses and results.

Segmental forecasting allows you to evaluate the company's activities in certain strategic areas, segments of strategic activity, and time horizons for the future:

- determining the factors of the internal and external environment;

- defining the goals and objectives of the existing strategy;

- assessment of new factors and events by business segment;

- forecasting the segmental strategy of the enterprise;

implementation and accounting of segmental policy based on accounting engineering tools;

- monitoring the current situation by business segment;

- evaluation of the results of segmental policy.

The assessment given to external situations and events at the forecasting stage is not stable. It can change under the influence of various factors, as a result of which the orientation of potential benefits, market opportunities, and development plans changes, which determines the need to use the mechanism of situational modeling, scenario approach, and the method of "decision trees".

Therefore, it is necessary to take into account the basic aspects of situational modeling, the development of economic situations in conditions of risk and uncertainty, alternative decision principles based on the use of situational derived balances and the decision tree mechanism:

- possible alternatives with access to property indicators;

- the likely consequences of each alternative; the level of probability of consequences; 
- presentation of the results of solving a situational problem in relation to the cost of the enterprise.

Since strategic accounting and forecasting are focused on the future, the main focus should be on maintaining the overall competitive strategy of the enterprise, taking into account strategic alternatives.

The organization of strategic segmental accounting and forecasting is based on the determination of the safety margin in order to assess the effectiveness of the segmental policy, which provides a comparison of the results of using the main areas of strategic activity, segments with the basic capital of the organization:

- the active safety margin determines the effectiveness of the segmental policy;

- passive safety margin characterizes economic losses;

a neutral (zero) margin of safety implies no effect.

When developing issues of segmentation, the organization of segmental accounting with the appropriate level of detail of information, it is necessary to proceed from the following positions:

- areas of application of segmentation: main activity, strategic initiatives, organizational structure, actions in the market;

- organizations of strategic accounting based on segmental market positioning and marketing planning;

- information capabilities of structured charts of accounts for the organization of segmental accounting, which allow you to organize analytical accounting with an information capacity of about 50-100 thousand analytical positions.

\section{Results and Discussions}

The model of strategic accounting of counterparties is presented in Figure 2.

The company's strategy for concluding contracts includes the channels for concluding contracts, tourist sources, the composition of suppliers, pricing policy, terms of delivery and settlement, etc. The following main areas of strategic analysis of counterparties are distinguished:

- the share of the supplier's services in the total volume of deliveries: large, medium, small suppliers;

- channels for the conclusion of contracts for tourist sources, domestic and regional market, outsourcing;

- supplier location: diverse geographical segments;

- tourist destinations served by the supplier of the enterprise;

- terms of delivery, quality of the service, the possibility of using alternatives, the time schedule for the provision of services and payments: a variety of time horizons in the form of cash flows of various durations;

- the nature of the relationship to the client: external, in the areas of activity, internal, dependent; 


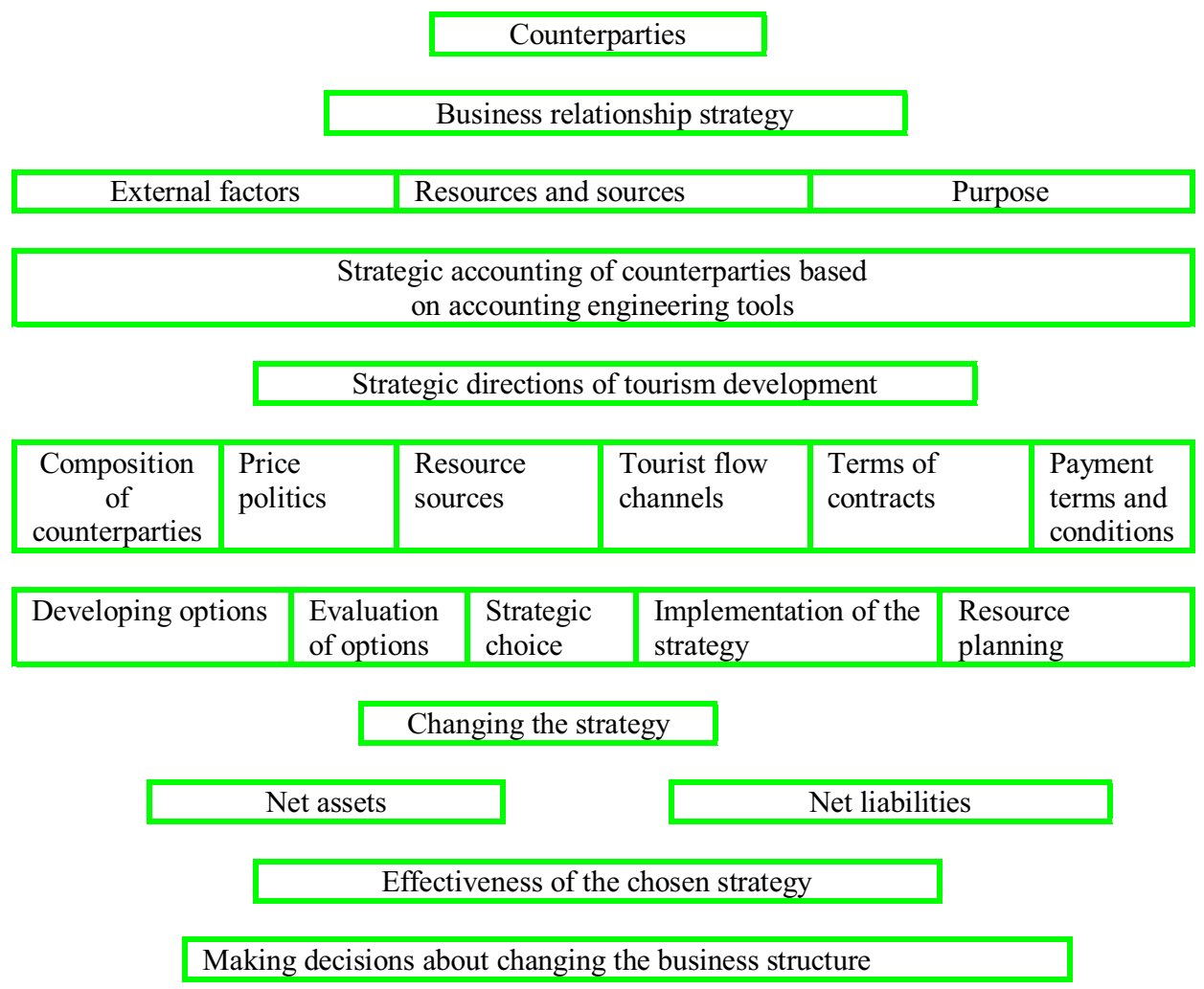

Fig. 2. Counterparty strategic accounting model.

- payment terms: advance payment, discounts for prompt payment of the amount for "loyalty", the installment payment;

- settlement currency: by type of settlement currency; supplier's competitive strength;

- the level of specialization of the service provider, the level of specialization of the travel agency in relation to the purchased travel services, - concentration on working with other customers, the importance of sales volume.

Travel service providers, if they have a great competitive strength, can put a travel agency in a very strong dependence on themselves. Therefore, when choosing suppliers, it is important to thoroughly and comprehensively study their activities and potential in order to be able to build a relationship with them that would provide the organization with maximum advantages when interacting with suppliers of tourist services and resources

The results of the supplier analysis are reflected in accounting based on accounting engineering tools in the form of:

- the aggregate indicator of ownership of net assets in the market valuation;

- a disaggregated indicator of the ownership of net liabilities in a fair valuation.

Comparison of the obtained indicators with the previously adopted strategy, the standard of resources allows us to determine the change in the financial condition of the tourist enterprise as a result of the transition to a new strategy.

The accounting engineering tool includes the use of separate sections of the structured chart of accounts, accounting records to reflect the adopted strategy for concluding contracts, transformed balance sheet, adjustment records to change the procurement strategy, adjusted resource balance, hypothetical records, hypothetical transformed balance sheet, allowing you to determine the zones of financial condition (active, passive, neutral) based on the accepted standard of resources and the value of the balance sheet, market and fair value of 
net assets and net liabilities.

\section{Conclucions}

The external positioning of a travel operator and the market valuation of its shares largely depend on the company's confident strategy and internal strategy management tools. The formation and implementation of the tourist product should be carried out on the basis of the proposed model of strategic accounting of counterparties. The use of this model makes it possible to carry out a strategic analysis of counterparties based on accounting engineering tools, taking into account external geographic and segmental factors, tourist resources, and adopted strategies for providing tourist services. The use of accounting engineering tools based on the use of a structured chart of accounts, adjusted accounting records, adjusted resource balance allows you to assess the strategic directions of the development of the tourism business and date estimates based on aggregated indicators of net assets and net liabilities.

The application of the proposed model allows the operator flexibility to changing external factors, to carry out a comparative assessment of options, making selection of an optimal, flexible to adapt to the change of strategy on the business, to plan resources regarding libraryhistory directions and the chosen strategy.

The methods of this article clearly show how important it is to build an adequate business management system based on the use of relevant accounting and analytical information obtained through the methods of strategic accounting, accounting engineering, and the use of a structured work plan of accounts.

\section{References}

1. J. Vinícius de Avila Pacheco, R. Morabito, Computers \& Industrial Engineering 61(6), 848-857 (2011) doi.org/10.1016/j.cie.2011.05.018

2. K. Boratyńska, E. Grzegorzewska, Journal of Business Research 89, 175-181 (2018) doi.org/10.1016/j.jbusres.2018.01.028

3. A. Kuzminov, T. Medvedskaya, N. Badvan, Financial research 1(58), 93-101 (2018)

4. P. Shumilin, Naukovedenie 4(13), 237 (2012) elibrary.ru/item.asp?id=18822664

5. E. Zaporozhtseva, Strategic analysis in business modeling procedures, Accounting and Statistics 4(48), 79-86 (2017)

6. V. Tkach, S. Shchemelev, European Research Studies Journal XX 3B, 326-332 (2017)

7. V. Tkach, V. Tkach, International journal of innovative science. Engineering \& Technology (IJISET) 10, 532-550 (2015)

8. N. Taleb, Antifragile. Things that Gain from Disorder (Kolibri, Azbuka-Atticus, M., 2017)

9. P. Wells, Journal of Accounting Education 42, 40-48 (2018) doi.org/10.1016/j.jaccedu.2017.12.003

10. A. Hellmann, H. Perera, C. Patel, Advances in Accounting 1(29), 124-133 (2013) doi.org/10.1016/j.adiac.2013.02.002

11. R. Drăgulescu (Ghiţă), A. Ilie, Procedia Economics and Finance 26, 272-277 (2015) doi.org/10.1016/j.sbspro.2013.12.589

12. S. Florina, O. Ecaterina, Accounting Procedia Economics and Finance 26, 272-277 (2015) doi.org/10.1016/S2212-56711500851-5 
13. K. Boratyńska, E. Grzegorzewska, Journal of Business Research 89, 175-181 (2018) doi.org/10.1016/j.jbusres.2018.01.028

14. G. Behzadi, M. O’Sullivan, T. Olsen, A. Zhang, Omega 79, 21-42 (2018) doi.org/10.1016/j.omega.2017.07.005

15. D. Zylbersztajn, Revista de Administração 52(1), 111-11 (2017) doi.org/10.1016/j.rausp.2016.10.004 